\title{
Ferrara metafísica: de De'Roberti a Antonioni, pasando por De Chirico
}

Iván Moure Pazos

ISS, CIAUD, USC

\section{RESUMEN}

El presente artículo pretende ser una sucinta antología por más de 500 años de arte ferrarés vinculado al concepto de lo metafísico. Desde el primer renacimiento a la inmediata contemporaneidad, lo metafísico se ha erigido como seña identitaria de la rica producción artística ferraresa, sirviendo de constante inspiración a los grandes artistas locales de la región emiliana. Lo que sigue, intenta poner de relevancia este hecho, remitiéndonos a los orígenes de esta querencia por el gusto ontológico, contraviniendo la afirmación oficial de lo metafísico como arte exclusivamente contemporáneo y dechiriquiano. También se abordará el concepto postmetafísico en el cine de Antonioni, cuestionándonos, nuevamente, el deceso de dicho movimiento.

\section{PALABRAS CLAVE:}

Ferrara, Metafísica, De Roberti, De Chirico, Antonioni.

\section{ABSTRACT}

This article is a brief anthology of over 500 years of Ferrara s art linked to the concept of the metaphysical. From the early Renaissance to the immediate contemporaneity, the metaphysical has emerged as the identifying attribute of the rich Ferrarese artistic production, serving as constant inspiration to great local artists from Emilia region. What follows, tries to highlight such fact, refering back to the origins of this fondness for the ontological taste, contravening the official concept, which states that the metaphysical art is a dechiriquiano, strictly contemporary art. The postmetaphysical concept will also be addressed on Antonioni s film works, leading to questioning, again, the death of named movement.

\section{KEY WORDS:}

Ferrara, Metaphysical, De Roberti, De Chirico, Antonioni. 
Ferrara! When no longer dwell The ducal chiefs within thee, shalt fall down, And crumbling piecemeal view thy hearthless halls, A poet s wreath shall be thine only crown, A poet s dungeon thy most far renown... Lord Byron, The Lament of Tasso, 1817

\section{Renacimiento metafísico $^{1}$}

La ciudad de Ferrara es, actualmente, conocida por su divulgada y consabida hegemonía cultural ejercida durante el primer Renacimiento "italiano":

"A finales del Quatrocentto y a lo largo de todo el Cinquecento, Ferrara deslumbra al mundo como ciudad eminentemente artística, convirtiéndose en una de las capitales culturales más importantes de occidente. El elenco de artistas, músicos y poetas de la denominada por Longhi como "officina ferrarese" es copioso. Ariosto, Tasso, Boiardo, Frescobaldi, Luzzaschi, Pisanello, Alberti, Van der Weyden, Bellini, Tura, Crevalcore, Del Cossa, Da Ferrara, Bastianino, Dossi, Bononi, Piero della Francesca o Mantegna, entre otros, configuran un centro artístico dificilmente parangonable. El efecto llamada no tarda en producirse, atrayendo las miradas de grandes artistas y científicos de la época. Montaigne, so pretexto de encontrarse con Tasso, visita Ferrara. No podrá olvidar jamás ‘el perfume de sus jardines'. Otros personajes ilustres como Paracelso o Copérnico se trasladan a la ciudad en busca de nuevas conquistas intelectuales llegando a doctorarse en su afamada universidad"2.

Se trata de la versión oficial, de una "estampa" de la Ferrara renacentista: una floreciente caterva de genios conviviendo en una modesta ciudad de apenas 40.000 habitantes. No desmentiremos dicha versión, documentada con rigor por grandes eruditos. Simplemente añadiremos una nueva lectura, otra capa de "barniz" a las ya dadas sobre la ciudad estense. Ferrara es la primera urbs metafísica creada ad hoc; una característica que se nutre de la fuerte tradición astronómica y astrológica desarrollada en la ciudad durante la primera época moderna.

1 Exceptuando el artículo de MOURE PAZOS, Iván, gran parte de la bibliografía citada se encuentra editada básicamente en italiano u otros idiomas extranjeros. Todos los textos citados han sido traducidos por el autor al castellano.

2 MOURE PAZOS, Iván, “Biagio Rossetti en Ferrara: el primer actante metafísico", (Actualmente en proceso de revisión por pares ciegos).
Todo comienza en 1912. Aby Warburg, haciendo gala de su peculiar astucia, desvela, en clave zodiacal, el significado iconográfico del Salone dei Mesi del Palazzo Schifanoia (1476-1484) de Ferrara ${ }^{3}$. Parafraseando a Gombrich, estamos ante "el momento culminante de la carrera de Warburg"4 . Se sugiere en esta revolucionaria investigación la implicación directa de Pellegrino Prisciani -consejero y astrólogo de los Este en la ciudad- en el programa iconográfico del $\mathrm{Sa}$ lone, abriéndose así, una nueva vía interpretativa al estudio de la simbología puesta en marcha por Leonello y Borso de Este en las postrimerías del Quattrocento ferrarés ${ }^{5}$. Esto vino a poner de manifiesto el enorme interés que la astrología suscitaba en la corte estense. No es casual que en dicha corte se conserve el tratado astrológico más importante de occidente: De Sphaera (1470). Se trata de la piedra rosetta utilizada por Warburg para descifrar el gran código simbólico de las pinturas del Salone dei Mesi ${ }^{6}$. Entre los ejecutores de aquellos magníficos affreschi se encontraba un joven visionario: Ercole de Roberti, en palabras de Vittorio Sgarbi, un "artista definitivamente metafísico"7:

"Los viajes a la luna, el hipogrifo, las esferas, los objetos suspendidos en el vacío y los refinados hallazgos arqueológicos, constituyen una anunciada iconografía de la metafísica entre el Quattrocento y el Cinquecento [...] Esta forzada relectura de la pintura ferraresa a la luz de una predisposición onírica, nos permite, a más de cuatro siglos del nacimiento de la metafísica, regresar a los origenes [...] Ferrara es, por lo tanto, el territorio más fértil en sueños, apariciones, visiones y pesadillas"8.

3 WARBURG, Aby, "Italienische Kunst und internationale Astrologie im Palazzo Schifanoja zu Ferrara”, in Adolfo VENTURI (Hrsg.), L'Italia e l'arte straniera, Atti del X Congresso Internazionale di Storia dell'Arte in Roma (1912), Rom 1922 (Reprint 1978), S. 179-193, Tafeln XXXVII-XLVI.

4 GOMBRICH, Ernst, Aby Warburg. Una biografia intellecttuale, Milano, Feltrinelli, 1983, p. 168.

5 DONATTINI, Massimo, "Pellegrino Prisciani a Venezia (marzo 1485-gennaio 1486)”, in Massimo DONATTINI (ed.), L Italia dell Inquisitore. Storia e geografia dell Italia del Cinquecento nella Descrittione di Leandro Alberti, Atti del convegno internazionale di Studi (Bologna, 27-29 maggio 2004), Bologna, Bononia University Press, 2007, pp. $187-217$.

6 WALTHER, Ingo; WOLF, Norbert, Chefs-d'œuvre de l'enluminure, Paris, Taschen, 2005, pp. 316-317.

7 SGARBI, Vittorio, Surrealismo Padano: da de Chirico a Foppiani 1915-1986, Milano, Skira, 2002, p. 13.

8 IBIDEM, pp. 13, 15. 


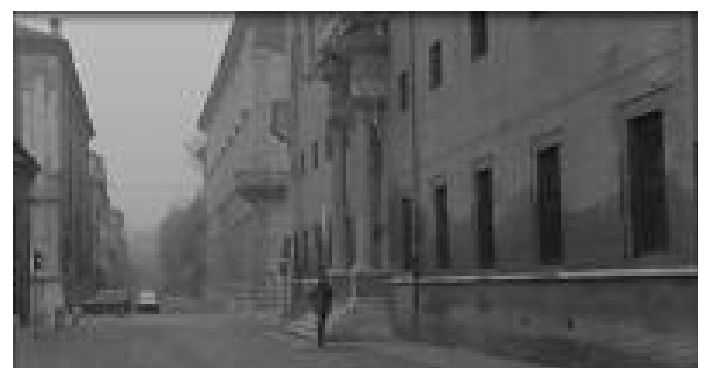

Fig. 1. Michelangelo Antonioni, Al di là delle nuvole (1995), 29:52

La fucina di Vulcano (1476-1480) del Palazzo Schifanoia o San Giovanni Battista (1480) son sintomáticas de esta querencia derobertiana, propiciando así una nueva mística metafísica en el Ducado estense del Quattrocento.

De manera análoga a la visionaria revolución pictórica de Ercole de Roberti, surge una figura enigmática. Se trata de Biagio Rossetti, urbanista y arquitecto de la corte y autor de la ampliación renacentista de la ciudad de Ferrara, considerado por Bruno Zevi como el primer urbanista moderno de occidente ${ }^{9}$ :

“En los primeros años de esta gran prosperidad cultural irrumpe en el panorama artístico de Ferrara la figura visionaria de Rossetti. Su aportación a la ciudad es tan generosa como bifaz. Por un lado altera el viejo entramado medieval erigiendo nuevos monumentos arquitectónicos, por otro crea una ciudad renacentista de grandes avenidas axiales de corte totalmente organicista; la llamada Terza Addizione Erculea"10.

En 1991 Carlo Bassi, publica los hallazgos de una larga investigación. Sus nuevos descubrimientos se encontraban a la altura de los realizados 80 años antes por Warburg. Rossetti no había trabajado sólo, sino que Pellegrino Prisciani, -recordemos, autor del programa astrológico del Palazzo Schifanoia- había dispuesto la idoneidad de las nuevas trazas urbanas y arquitectónicas en base al quadrato astrologico de los Este en el cual, el Palazzo Diamanti (1493-1503) actuaría como núcleo solar ${ }^{11}$. De nuevo, Ferrara se

9 ZEVI, Bruno (1960), Saper vedere la città. Ferrara di Biagio Rossetti: La prima città moderna europea, Torino, Einaudi, 1997, p. 204.

10 MOURE PAZOS, Iván, op., cit, s/p.

11 BASSI, Carlo (1991), Perché Ferrara è bella. Guida alla comprensione della città, Ferrara, Gabriele Corbo, 2008, pp. 295-304; del mismo autor, "Il senso della cittá, ovvero le geometrie segrete di Ferrara”, Giardini e Palazzi rinascimentali di Ferrara, sviluppo urbanistico moderno, a cura di M. R. DI FABIO, Ferrara, Agea, 1996, pp. 9-17; FOLIN, Marco, "La proportionabilis et commesurata de-

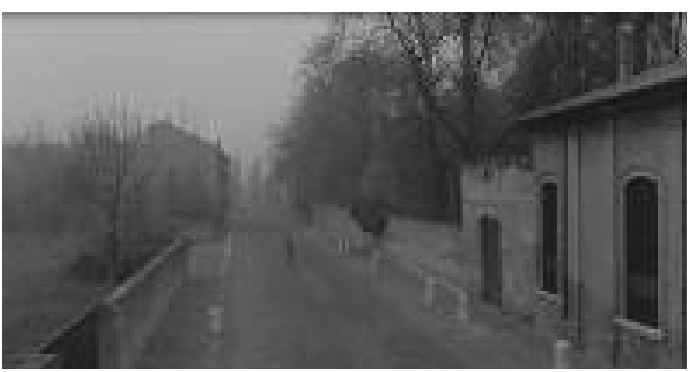

Fig. 2. Michelangelo Antonioni, Al di là delle nuvole (1995), 31:05

revelaba como una ciudad que transcendía el ámbito de lo real para posicionarse en un terreno decididamente cósmico, astral y metafísico. No había dudas al respecto: el grueso de las grandes producciones artísticas de la Ferrara del renacimiento gravitaban entorno a ese llamado "orden solar de la nueva metafísica"12. La totalidad de la Terza Addizione Erculea, así como las principales iglesias y palacios que la componen, estuvieron supeditados a la ciencia de la disciplina astrológica. Ferrara fue la primera ciudad del renacimiento donde el arte y la astrología se dieron la mano, condicionando y propiciando así una suerte de cultura metafísica inherente a la ciudad:

"Se trata de la única ciudad italiana cuyo horizonte no se ve interrumpido por ningún accidente geográfico. La única, en la cual, sus límites de borde tienden al infinito [...] Sus calles alargadas, sus perspectivas inalcanzables, son un auténtico disparadero para la "fuga” metafísica. La agorafóbica predisposición a la horizontalidad implica a la trascendentalidad del ser. Las coordenadas espaciotiempo se difuminan y nuestra perspectiva de la ciudad termina por "dislocarse" en una suerte de reflexión introspectiva" ${ }^{13}$.

\section{La pintura metafísica}

Tan sólo tres años después de la primera contribución iconográfica de Warburg para el $\mathrm{Pa}$ -

signatio urbis Ferrariae di Pellegrino Prisciani (14941495)", in Rappresentare la città. Topografie urbane nell Italia di antico regime, a cura di Marco FOLIN, Reggio Emilia, Diabasis, 2010, pp. 99-120; INCERTI, Manuela, "Astronomia e Astrologia nel disegno della forma urbana: il caso di Ferrara e Bologna”, in Bruniana and Campanelliana, 2, 2010, pp. 639-647.

12 PASQUALI, Marilena, "Carrà e Ferrara, 1917", in Carlo Carrà 1881-1966, a cura di Augusta MONFERINI, MilanoRoma, Electa-Elemond Editori Associati by Galleria Nazionale d'Arte Moderna di Roma, Exposizione (15 de diciembre 1994-28 febbraio 1995), 1994, pp. 89-96.

13 MOURE PAZOS, Iván, op., cit, s/p. 
lazzo Schifanoia, De Chirico "aterriza” en la ciudad para revolucionar la pintura -y la literatura- contemporánea:

“En 1915, De Chirico, Carrà, Morandi y de Pisis fundaban en Ferrara uno de los movimientos artísticos más influyentes del Siglo XX: la pintura metafísica. A partir de entonces, la fama de Ferrara crecerá paralela a la repercusión vanguardista, situándose por primera vez en el punto de mira de la crítica internacional contemporánea. Rossetti había creado, cinco siglos antes, el escenario propicio para el "estallido" metafísico. Las alusiones a su obra, aunque implícitas, son incontables. I giocattoli del principe (1915), I progetti della fanciulla (1915), Interno metafisico (1917), Il grande metafisico (1917) o Le muse inquietanti (1918) -manifiesto dechiriquiano por excelencia-, entre otras muchas telas, son sintomáticas de este empeño por ensalzar al visionario genio rossettiano" ${ }^{14}$.

Ferrara, representaba para De Chirico la ciudad de la "geométrica belleza" ${ }^{15}$, la "ciudad solitaria" ${ }^{16}$, la "ciudad de la potencia metafísi-

14 IDEM.

15 DE CHIRICO, Giorgio, “Gaetano Previati”, in Il Convegno, 7, 1920, pp. 29-36.

16 IDEM. Resulta curiosa la uniformidad urbana que Ferrara ha mantenido a lo largo del tiempo. Muchas de estas señas identitarias reseñadas por De Chirico y sus colegas metafísicos, coinciden con algunas anotaciones realizadas por los viajeros del Grand Tour. Resaltamos, a continuación, un fragmento bastante ilustrativo firmado por del erudito francés DE BROSSES, Charles (1799), Viaggio in Italia. Lettere familiari, Bari-Roma, 1992, pp. 171173: "La ciudad de Ferrara es vasta y espaciosa. Son éstos, creo, los adjetivos que la definen, vasta, porque es grande y desierta; espaciosa porque se puede pasear cómodamente por sus magníficas calles trazadas a escuadra y de una longitud impresionante [...] Pecado que la ciudad esté desierta; no por ello es menos bonita, y esto no tanto por sus magníficos palacios, sino por la uniformidad de sus edificios. En general, están todos hechos de arcilla y habitados por gatos persas, al menos, otro ser viviente, no veremos en las ventanas". La literatura metafísica incidió y se "regodeó" en ese omnipresente silencio ferrarés que incitaba a una irrefrenable búsqueda metafísica del ser. SAVINIO, Alberto (1918), "Hermaphrodito", in Alberto SAVINIO, Hermaphrodito e altri Romanzi, a cura di Alessandro TINTERRI, Milano, Adelphi, 1995, p. 27: "Por Luna y Venus, bajan por la ciudad cuadrada, en largas filas serpenteantes, una población muda y ciega, de seres parecidos a cosas de la naturaleza -minerales, vegetales- [...] Ferrara es la ciudad de los mil misterios naturales". Asimismo, las alusiones a este silencio metafísico de las desérticas calles ferraresas, se evocan, de manera continuada, en el libro de DE PISIS, Filippo (1923), La città dalle cento meraviglie, Firenze, Vallechi, 1995, pp. $14,55,72,75,81,83,86,95,137,140,141,142,143$, 150, 166, 178, 179, 185. ca" ${ }^{17}$, pero también es la ciudad cósmica que "enciende" sus primeros coqueteos con la ciencia astrológica, llegando a conocer e interesarse por los estudios del célebre astrónomo ferrarés -y amigo- Giorgio Bongiovani ${ }^{18}$. Puede que este condicionamiento metafísico y cósmico de la ciudad incite a la transitoria "locura" sicalíptica y paranoica de sus habitantes:

"Los ferrareses son personas terriblemente libidinosas, especialmente en la alta primavera, cuando la libido que se cierne sobre Ferrara deviene en una fuerza tal, que se siente casi el rumor, como de agua torrencial o de fuego flameante. El profesor Tramboni, insigne frenólogo y director del manicomio de Ferrara, me explicó que este estado anormal de los ferrareses es debido a la exhalación del cáñamo y a la continua humedad [...] Tramboni afirmaba que el manicomio de Ferrara, de todos los de Italia, es aquel que albergaba más locos. Yo mismo puedo constatar que en Ferrara se encuentran personas extrañas en abundancia y por lo tanto personas extremadamente interesantes. Ese punto de locura generalizada en Ferrara, hace que tanto poetas, como científicos y pintores de esa ciudad se sumerjan con mayor énfasis y mayor profundidad en su sueño, en el sueño de aquella actividad hacia la que se sienten fatalmente empujados durante su estancia en esta ciudad. Todo gira en torno al centro urbano de aquella ciudad tan profundamente metafísica y tan justa y ordenada en sus líneas, que Burckhardt ha definido, por algo, como la ciudad más moderna del mundo"19.

La idea de De Chirico sobre la Ferrara metafísica y astral, coincidirá plenamente con la de sus colegas metafísicos. De Pisis dedica un libro entero a la ciudad en la misma clave de ciudad metafísica y cósmica, La città dalle cento meraviglie (1923) y Savinio -hermano de De Chirico- la inmortalizará de igual manera en su célebre Hermaphrodito (1918). Personajes paranoicos y excéntricos pueblan el mejor repertorio de la literatura metafísica. Condes fe-

17 IDEM

18 DE CHIRICO, Giorgio (1940), “Achille Funi”, in Giorgio DE CHIRICO, Scritti/1. Romanzi e Scritti critici e teorici (19111945), a cura di Andrea CORTELLESA, Milano, Bompiani, 2008, pp. 883-889; Del mismo autor (1945), Memorie della mia vita, Ferrara-Matera, La bautta, 1985, p. 89; DE SETA, Cesare, La cultura architettonica in Italia, tra le due guerre, Roma-Bari, Laterza, 1989, p. 118.

19 DE CHIRICO, Giorgio (1945), Memorie della mia vita, op. cit., pp. 90-91; Del mismo autor (1940), "Achille Funi”, op. cit., pp. 883-889. 
llinianos, astrónomos consumados, meteorólogos anancásticos, misántropos, taxidermistas y un largo etcétera de curiosos individuos convergen en la llamada "ciudad de Worbas"20:

"En el planeta esférico, vagando en el vacío (ien el infinito pensará con temor un metafísico!) que se llama la tierra, el mundo, las regiones que emergen del nivel del agua, las ciudades, los paises, en las calles habitan y caminan los hombres. Hombres de todos los países, hombres de todas las calles, pensemos!"21.

\section{Postmetafísica antonioniana}

Coincidiendo con el gran apogeo vanguardista de la pintura metafísica, nace en la ciudad estense Michelangelo Antonioni. Por aquel entonces, Ferrara comenzaba a posicionarse como uno de los enclaves fundamentales de la cinematografía italiana. No estará de más apuntar que entre 1902 y 2015 se realizaron en esta modesta ciudad de provincias más de 250 filmes, algunos de ellos, clásicos fundamentales de la historia del celuloide ${ }^{22}$.

Antonioni vive en Ferrara los primeros 27 años de su vida antes de emprender su marcha a Roma. La pulsión metafísica de su ciudad natal se convertirá en una constante a lo largo de su extensa carrera cinematográfica. Como un leit motiv perdurable en el tiempo, Ferrara parece tener la cualidad de imprimir a sus habitantes, a través de una extraña comunión artística, una permanente sensibilidad introspectiva, existencialista y cósmica. De Ercole de Roberti a Antonioni, pasando por De Chirico, todos parecen haber sucumbido a una suerte de melancolía metafísica tremendamente afín. Del primer renacimiento a la última contemporaneidad, Ferrara, como bien apunta Vittorio Sgarbi, es "siempre la misma"23.

Antonioni, de manera explícita, rinde homenaje a su ciudad -y alrededores- en varias de sus producciones cinematográficas. Gente del Po (1943-1947), Cronaca di un amore (1950), Il Grido (1957), Il deserto rosso (1963), Al di là delle nuvole -codirigida con Wim Wenders- (1995), son

20 DE PISIS, Filippo (1923), op cit., p. 115. DE CHIRICO, Giorgio (1940), “Achille Funi”, op . cit., pp. 883-889; SAVINIO, Alberto (1918), op. cit., pp. 26-33.

21 DE PISIS, Filippo (1923), op. cit., p. 140.

22 MICALIZZI, Paolo, Al di là e al di qua delle nuvole: Ferrara nel cinema, Firenze, Aska, 2004, p. 19.

23 SGARBI, Vittorio, "Ferrara, Città d'Arte", en VV. AA., Ferrara, Milano, Franco Maria Ricci, 2002, pp. 25-42. sintomáticas de su querencia por el territorio y el paisaje ferrarés ${ }^{24}$ : "Las calles anchas y largas, calles de ciudad de llanura, bellas y tranquilas, que invitan a la elegancia, a la ociosidad disipada [...]"25 [Figs. 1-2]. Y es que muchos de estos fotogramas nos remiten a un patrimonio afectivo totalmente dechiriquiano, metafísico y ferrarés. Con razón Bruno Racine a propósito de Cronaca di un amore -en su artículo de reciente aparición- referencia este paisaje como característico de su obra:

“Anchas calles rectas y vacías, una atmósfera cerrada y plomiza, en la que todo el mundo espía a todo el mundo, así aparece la ciudad en la película de Antonioni; irremediablemente provincial, perfecta antítesis de Milán, la metrópoli palpitante donde el silencio y la soledad no existen más que en el corazón de la noche" 26 .

Y sobre ello vuelve el propio Antonioni al referirse a los paisajes que pueblan Il grido:

"[....] he querido reflejar el paisaje de la memoria, el paisaje de mi infancia. Visto con los ojos del que regresa a casa después de una intensa experiencia cultural y sentimental. En Il grido este retorno tiene lugar en la estación más favorable, en invierno, cuando el horizonte completamente libre se contrapone a la psicología del personaje central del film"27.

Otro de los aspectos iconográficos que no debemos pasar por alto en la producción cinematográfica de Antonioni, son sus continuas y explícitas referencias iconográficas a la tradición artística de la escuela ferraresa. En sus múltiples escritos, Antonioni incide constantemente en su deuda con los grandes pintores y arquitectos tratados en el primer y segundo epígrafe de este artículo. Ercole de Roberti, Piero della Francesca, Cosmè Tura, Federico del Cossa, Dosso Dosi, Biagio Rossetti -de forma implícita-, De Pisis, Mo-

24 TASSONE, Aldo, I film di Michelangelo Antonioni: un poeta della visione, Roma, Gremese Editore, 2002, p. 5.

25 ANTONIONI, Michelangelo, "Il mio cinema", in Fare un film è per me vivere: scritti sul cinema, a cura di Carlo DI CARLO e Giorgio TINAZZI, Venezia, Marsilio, 1994, pp. 5-69.

26 RACINE, Bruno, “Antonioni, Bassani e Ferrara”, in Lo squardo di Michelangelo Antonioni e le arti, a cura di Dominique PAÏNI, Ferrrara, Fondazione Ferrara Arte. Exposizione nel Palazzo Diamanti (10 marzo- 9 giugno 2013), 2013, pp. 194-199.

27 ANTONIONI, Michelangelo, “All'origine del cinema c'è una scelta", in Fare un film è per me vivere: scritti sul cinema, op. cit, pp. 121-129. 


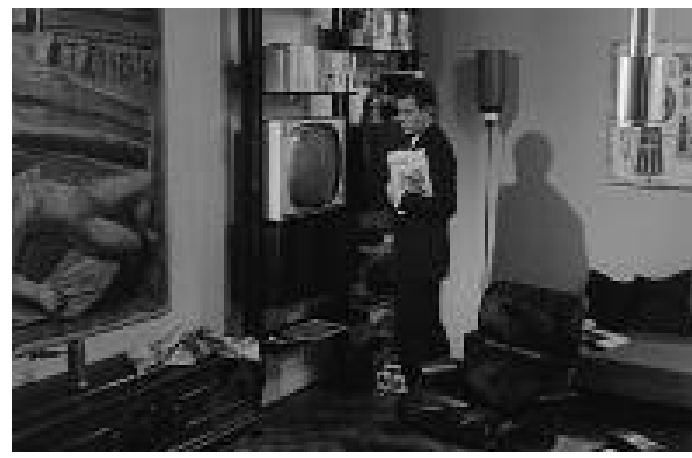

Fig. 3. Michelangelo Antonioni, La notte (1961), 28:50

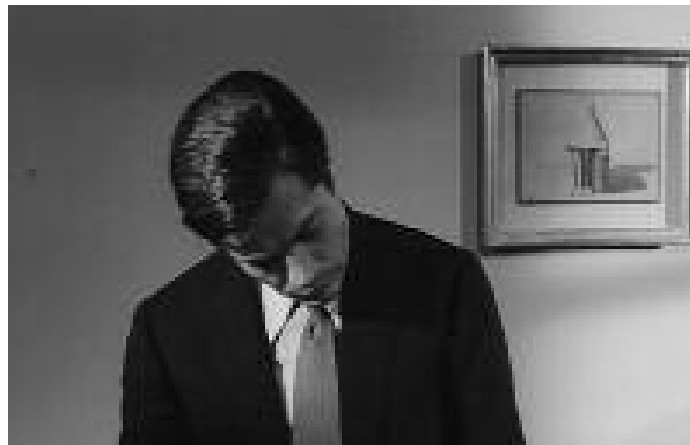

Fig. 4. Michelangelo Antonioni, La notte (1961), 29:21

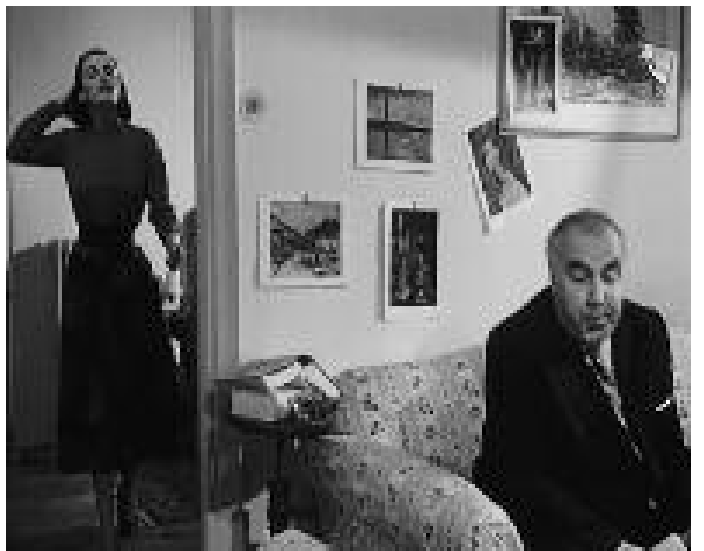

Fig. 5. Michelangelo Antonioni, La signora senza camelie (1953), $29 \cdot 32$

randi, o De Chirico, entre muchos otros, son citados como las piedras angulares de su cine ${ }^{28}$. Por lo tanto, no ha de extrañarnos que en La notte (1961), concretamente en el salón del escritor Giovanni Pontano, -interpretado magistralmente por Marcelo Mastroianni-, se muestre la La caduta de Mario Sironi, así como otra tela desconocida de Massimo Campigli ${ }^{29}$ [Fig. 3]. Pero

28 ANTONIONI, Michelangelo, "Conversazione”, in Fare un film è per me vivere: scritti sul cinema, op. cit, pp. 204216; del mismo autor, "Identificazione di un Regista", in Fare un film è per me vivere: scritti sul cinema, op. cit, pp. 216-229.

29 GUIDI, Barbara, "Sono un amante della pintura", in Lo squardo di Michelangelo Antonioni e le arti, op . cit., pp. todavía hay más, en el despacho del escritor también nos encontramos con una naturaleza muerta de Morandi ${ }^{30}$ [Fig. 4]. En otras ocasiones, como en el caso de La signora senza camelie (1953), Antonioni introduce dos de las obras más icónicas y representativas de la metafísica ferraresa: Il duo (1915) y Le muse inquietanti -anteriormente citada-, ambas de De Chirico ${ }^{31}$ [Fig. 5].

"Antonioni, a menudo, utiliza las obras de arte con la intención de caracterizar ambientes y personajes [...] La admiración por De Chirico, que ha influenciado muchísimo al director, queda constatada en el hecho de que el propio cineasta tuviese en su colección artística una composición metafísica titulada Le jour d eté"32.

Éstas pudieran ser algunas de las pruebas más evidentes y explícitas del amor que Antonioni profesaba a su ciudad natal, pero lo cierto es que, como bien apunta Guido Fink, "es difícil negar que todas las ciudades de Antonioni, son siempre, y en ciertos aspectos, Ferrara" ${ }^{33}$. Fink se refería a la influencia implícita de Ferrara en gran parte de sus filmes, incluso, en aquellos rodados en lugares tan dispares como Asia o América. Baste recordar el flashback a Ferrara en la realización de Chung Kuo (1972) al contemplar aquella larga fila de chinos andando en bicicleta ${ }^{34}$.

Otra de las referencias implícitas a la Ferrara metafísica se evidencia en la utilización reiterada del recurso de la niebla. Ferrara es la más neblinosa de todas las ciudades italianas, siendo ésta una de las características más reconocibles de su climatología: "La niebla del valle padano es la primera cosa que sus ojos ven ${ }^{35}$ ": "El resto es niebla. Estoy habituado. Aquella que circunda nuestras ensoñaciones y aquella de Ferrara. Aquí, en invierno cuando descendía me gustaba caminar por las calles. Era el único momen-

259-263; PAÏNI, Dominique, "Scomparse", in Lo sguardo di Michelangelo Antonioni e le arti, op cit., p. 93.

30 GUIDI, Barbara, op. cit., pp. 216-229.

31 IDEM

32 IDEM

33 FINK, Guido, "Bisogna nascere", in Lo sguardo di Michelangelo Antonioni e le arti, op. cit., pp. 178-193.

34 Se apunta aquí un dato banal para el italiano pero interesante para foráneos: Ferrara es la ciudad de Europa con más bicicletas por habitante, convirtiéndose en una de sus principales señas identitarias. Esto explicaría el citado flash back de Antonioni al que se hace referencia en el texto. MICALIZZI, Paolo, "Ferrara e Antonioni", in Michelangelo Antonioni: Ferrara 1993, Ferrara, Cartografia Artigiana, 1993, pp. 32-34.

35 PAÏNI, Dominique, "Autor", in Lo sguardo di Michelangelo Antonioni e le arti, op. cit., p. 43. 
to en el que podía pensar en ser otro" ${ }^{36}$. Con razón apostilla Fink, "las ciudades de Antonioni son el escenario metafísico de una añoranza, de un vacío, de una extrañeza"37. Antonioni supera el realismo interiorizándolo en una suerte de imprimación metafísica -la misma que De Roberti, Rossetti y De Chirico- jugando constantemente con la vocación escenográfica de su ciudad. El paisaje ferrarés "como sustancia primera en el narrar, como concreción histórica e instrumento de indagación exponencialmente abstracto, metafísico [...]"38. De forma atinada, Païni refiriéndose a su trilogía, L avventura (1960), La notte (1961) y el L Eclisse (1962), aclara: "todas ellas infunden al cine de Antonioni un silencio homólogo a las naturalezas muertas de Morandi, a las visiones deshumanizadas de los paisajes urbanos de Sironi, o las arquitecturas dechiriquianas que testimonian la suspensión de un tiempo pasado"39. Quisiera, como colofón final, concluir este epígrafe parafraseando al propio Antonioni:

"Yo he dejado Ferrara, hace muchos años, llevando conmigo un equipaje de afectos e imágenes que he portado siempre a todas las partes donde me he dirigido. Yo creo que quien deja su ciudad, la ciudad donde fue joven, lo pierde todo. Estoy convencido de esto: la experiencia me ha enseñado esto" ${ }^{40}$.

\section{Conclusiones}

Abríamos este artículo incidiendo en las claves fundamentales y fundacionales que propiciaron el asentamiento de un gusto metafísico en la larga tradición artística ferraresa. Después de este largo recorrido, podemos afirmar que aquella "protometafísica" de edad moderna se revela como el germen primigenio de lo que posteriormente se denominó como movimiento metafísico; una de las principales banderas izadas de las vanguardias europeas. Cabría preguntarse cuanto hay de originalidad y cuanto de deuda precedente en dicha revolución artística. Las nuevas conquistas paisajísticas alcanzadas

36 ANTONIONI, Michelangelo, Quel bowling sul Tevere, Torino, Einaudi, 1995, p. 85.

37 FINK, Guido, op, cit., pp. 178-193.

38 SEMERARO, Stefano "Professione regista: il paesaggio nel cinema di Michelangelo Antonioni”, in Informazioni, commenti, inchieste sui beni culturali, 3, 1997, pp. 51-54.

39 PAÏNI, Dominique, "Scomparse", op . cit., p. 93.

40 MICALIZZI, Paolo, "Ferrara e Antonioni”, op. cit., pp. 3234. por Ercole de'Roberti en el ámbito pictórico sentaron las bases de futuras innovaciones artísticas en suelo ferrarés. En paralelo, Rossetti y Prisciani transformaron esta ilusión bidimensional en real tridimensionalidad a través de un proyecto tan ambicioso como renovador: la Terza Addizione Erculea. Al calor de los nuevos postulados científicos y astrológicos se había configurado el contexto urbano necesario para el desarrollo de posteriores experimentaciones artísticas, ya fueran pictóricas, literarias o cinematográficas. Secundando a Vittorio Sgarbi y Bruno Zevi no podemos pasar por alto esta idea -un tanto descorazonadora para la historiografía contemporánea- basada en un origen moderno del movimiento metafísico ferrarés. Incontables son las telas de De Chirico, Carrà, Morandi o de Pisis que hunden sus raíces en la herencia metafísica moderna. De igual modo, cualquiera que se acerque a la literatura metafísica del momento advertirá sobre este fructífero diálogo secular. ¿Acaso no es la obra Rossetti la protagonista del Hermaphrodito o de La cittá dalle cento meraviglie? Todo converge en esta suerte de introspección teleológica. Es cierto que Ferrara no necesitaba muchos "estímulos artísticos" para erigirse como iconográfica ciudad metafísica. Su propio emplazamiento orográfico y peculiar climatología bastaban. De Roberti y Rossetti transformaron esta herencia intrínseca, -estrechamente vinculada a la trascendentalidad del ser-, en arte. Con ello, la ciudad de Ferrara se convierte en protagonista indiscutible de una reconocible tradición artística. Llegados a este punto, cabe preguntarse si el deceso metafísico sentenciado por los críticos, -coincidiendo con el tsunami surrealista-, fue tal o simplemente un espejismo estructurador de carácter clasificador. No entraremos a valorar cuanto debe el surrealismo a la metafísica. Simplemente recordar el título del libro -anteriormente citado- de Sgarbi dedicado a De Chirico: Surrealismo Padano. Puede que aquel tímido movimiento artístico de provincias fuese rápidamente engullido por aquel gigante surrealista con capital en París, pero lo cierto es que, mientras eso ocurría, en la propia ciudad de Ferrara, Antonioni tomaba el relevo de la originaria y larga tradición metafísica de su ciudad. Sus obras fílmicas y escriturales así lo atestiguan. ¿Se trataba de una postmetafísica, de la natural continuación de un movimiento, o simplemente de una tradición artística ferraresa? La última opción parece bastante factible. La metafísica en Ferrara es folclore. El característico vitalismo italiano se entrevera en la ciudad de Ferrara de melancólico existencialismo. Como 
ejemplo rápido e ilustrativo, baste pensar, a vuelapluma, en la exaltación vital de las obras fellinianas en contraposición a la reflexión metafisica y atonal de la obra antoniniana. Ambos son de la misma región Emilia-Romagna, pero Fellini es riminiano, no ferrarés, por lo tanto, no comprende la cultura del silencio, contemplativa, monacal y pacificante de la tradición metafísica ferraresa. Resulta sorprendente constatar, a lo largo de todas estas páginas, la linealidad existente entre la primera protometafísica renacentista, la oficial metafísica contemporánea y la posterior "postmetafísica" antoniniana.
Pero lo realmente sorprendente es que, una ciudad de provincias, de corte aristocrático-agrícola como Ferrara -de escasísima población y ajena al rico eje industrial Modena-Parma-Bologna-, haya conseguido convertirse en indiscutible referente artístico internacional. Protagonista de algunos de los acontecimientos más señeros de la historia del arte, Ferrara, siempre ha exportado obras de excelente factura artística. Lo curioso es que éstas, siempre han gravitado entorno a la idea de lo metafísico, convirtiéndose, andando el tiempo, en la principal seña identitaria de la ciudad emiliana. 